\title{
Therapeutic factor VIII levels and negligible toxicity in mouse and dog models of hemophilia A following gene therapy with high-capacity adenoviral vectors
}

Marinee K. L. Chuah, Gudrun Schiedner, Lieven Thorrez, Brian Brown, Marion Johnston, Veerle Gillijns, Sabine Hertel, Nico Van Rooijen, David Lillicrap, Désiré Collen, Thierry VandenDriessche, and Stefan Kochanek

\begin{abstract}
High-capacity adenoviral (HC-Ad) vectors expressing B-domain-deleted human or canine factor VIII from different liverspecific promoters were evaluated for gene therapy of hemophilia A. Intravenous administration of these vectors into hemophilic FVIII-deficient immunodeficient SCID mice (FVIIIKO-SCID) at a dose of $5 \times 10^{9}$ infectious units (IU) resulted in efficient hepatic gene delivery and longterm expression of supraphysiologic FVIII levels (exceeding $15000 \mathrm{mU} / \mathrm{mL}$ ), correcting the bleeding diathesis. Injection of only $5 \times 10^{7}$ IU still resulted in therapeutic FVIII levels. In immunocompetent hemophilic FVIII-deficient mice (FVIIIKO), FVIII expression levels peaked at 75000
\end{abstract}

$\mathrm{mU} / \mathrm{mL}$ but declined thereafter because of neutralizing anti-FVIII antibodies and a cellular immune response. Vector administration did not result in thrombocytopenia, anemia, or elevation of the proinflammatory cytokine interleukin-6 (IL-6) and caused no or only transient elevations in serum transaminases. Following transient in vivo depletion of macrophages before gene transfer, significantly higher and stable FVIII expression levels were observed. Injection of only $5 \times 10^{6} \mathrm{HC}$-Ad vectors after macrophage depletion resulted in long-term therapeutic FVIII levels in the FVIIIKO and FVIIIKO-SCID mice. Intravenous injection of an HC-Ad vector into a hemophilia $A \operatorname{dog}$ at a dose of
$4.3 \times 10^{9} \mathrm{IU} / \mathrm{kg}$ led to transient therapeutic canine FVIII levels that partially corrected whole-blood clotting time. Inhibitory antibodies to canine FVIII could not be detected, and there were no signs of hepatotoxicity or of hematologic abnormalities. These results contribute to a better understanding of the safety and efficacy of HC-Ad vectors and suggest that the therapeutic window of HC-Ad vectors could be improved by minimizing the interaction between $\mathrm{HC}$-Ad vectors and the innate immune system. (Blood. 2003;101:1734-1743)

() 2003 by The American Society of Hematology

\section{Introduction}

Hemophilia A results from a deficiency in factor VIII (FVIII) that is characterized by spontaneous and prolonged bleeding in the joints, muscles, and internal organs. ${ }^{1}$ Currently, hemophilia is treated with protein replacement therapy using either plasma-derived or recombinant FVIII. Although FVIII replacement markedly improves the life expectancy of patients with hemophilia, they are still at risk for severe bleeding episodes, chronic joint damage, and viral transmission from contaminated blood sources. Gene therapy could be an attractive alternative for the treatment of hemophilia A because the therapeutic window is relatively broad and levels slightly higher than $1 \%$ of normal physiologic levels are therapeutic. ${ }^{2}$ If successful, gene therapy could provide constant FVIII synthesis that may lead to a cure for this disease.

Different viral and nonviral gene therapy methods have been evaluated for the treatment of patients with hemophilia A. ${ }^{3,4}$ Adenoviral (Ad) vectors are the most efficient vectors for hepatic gene delivery. ${ }^{3,4}$ The adenoviral vector genome remains extrachromosomal, implying that the risk for neoplastic transformation from insertional mutagenesis is low. However, early-generation adenoviral vectors still contain most viral genes. Their expression contributes to inflammatory responses, toxicity, and short-term transgene expression. ${ }^{5-10}$

Previous studies have shown that injection of early-generation adenoviral vectors encoding canine or human FVIII resulted in efficient liver transduction and in therapeutic levels of FVIII in hemophilic mice, dogs, and rhesus macaques. ${ }^{11-15}$ However, FVIII levels declined to baseline, possibly because of vector toxicity related to residual adenoviral gene expression. In the dog model, the induction of a humoral immune response against FVIII was associated with only transient correction of the bleeding diathesis. ${ }^{15}$ Inflammatory responses and vector toxicity further diminished therapeutic efficacy. ${ }^{15}$

To overcome the limitations of early-generation adenoviral vectors, novel adenoviral vectors have been developed, designated as high-capacity (HC) adenoviral vectors, devoid of all adenoviral genes. These HC-Ad vectors retain only the necessary cis-acting elements required for generating infectious vector particles during
From the Center for Transgene Technology and Gene Therapy, Flanders Interuniversity Institute for Biotechnology, University of Leuven, Belgium; Center for Molecular Medicine, University of Cologne, Germany; Department of Pathology, Queen's University, Kingston, ON, Canada; and Department of Cell Biology and Immunology, Vrije Universiteit, Amsterdam, The Netherlands.

Submitted March 15, 2002; accepted October 8, 2002. Prepublished online as Blood First Edition Paper, October 24, 2002; DOI 10.1182/blood-2002-03-0823.

Supported by the Flemish Fund for Scientific Research (FWO) (G.0110.00), the Flemish government, Canadian Institutes of Health Research (grant MOP10912), the German Federal Ministry of Education and Research (FKZ: 01KS9502), and the Center for Molecular Medicine Cologne (ZMMK) (S.K.). D.L. is the recipient of a Canada Research Chair in Molecular Hemostasis. L.T. is an Instituut voor de aanmoediging van innovatie door Wetenschap en Technologie in Vlaanderen (I.W.T.) doctoral fellow.

M.K.L.C. and G.S. contributed equally to this work.

Reprints: Thierry VandenDriessche, Center for Transgene Technology and Gene Therapy; Flanders Interuniversity Institute for Biotechnology, University of Leuven, 49 Herestraat B-3000 Leuven, Belgium; e-mail: thierry.vandendriessche @med.kuleuven.ac.be.

The publication costs of this article were defrayed in part by page charge payment. Therefore, and solely to indicate this fact, this article is hereby marked "advertisement" in accordance with 18 U.S.C. section 1734.

(C) 2003 by The American Society of Hematology 
vector production, and they depend on the use of an E1complementation cell line and a packaging-defective helper virus that provides the necessary viral functions in trans. ${ }^{16,17}$

In the present study, we evaluated whether HC-Ad vectors encoding FVIII could be used to cure hemophilia A in a clinically relevant animal model. HC-Ad vectors expressing human or canine B-domain-deleted FVIII genes from different liver-specific promoters were injected into FVIII-deficient mice with hemophilia A. Efficiency of liver gene transfer, biodistribution, biosafety, and specific or innate immune responses were analyzed. In immunodeficient FVIII-deficient mice, hepatic gene transfer resulted in long-term expression of human or canine FVIII at supraphysiologic levels, correcting the bleeding disorder. In immunocompetent mice, neutralizing antibodies were induced that were directed against FVIII. Following transient in vivo depletion of Kupffer cells and lymphoid (splenic) macrophages, stable FVIII expression and significantly higher FVIII levels were observed in most animals. Serum transaminase levels and cytokine profiles confirmed the safety of this new generation of adenoviral vectors. The use of canine FVIII genes was important in the preparation of efficacy and safety studies in hemophilic dogs. Subsequent injection of this HC-Ad vector into a hemophilia A dog resulted in therapeutic FVIII levels and confirmed the relative safety of these improved vectors in a clinically relevant large animal model.

\section{Materials and methods}

\section{Construction of the B-domain deleted-FVIII cDNA}

Human B-domain-deleted $F V I I I$ cDNA was generated by polymerase chain reaction (PCR) cloning starting from the pSP64-FVIII clone, originally obtained from the American Type Culture Collection (Rockville, MD), containing the full-length FVIII cDNA. This particular human B-domaindeleted FVIII cDNA had several unique features that were intended to increase gene expression. Kozak translational consensus was included to increase translational efficiency. A TAA stop codon was used instead of a $T G A$ stop codon because of its greater efficiency. In addition, the $3^{\prime}$ untranslated region (UTR) was deleted because it may inhibit gene expression. ${ }^{18}$ The B-domain deletion started at amino acid Ser741, retaining the 740 thrombin cleavage site, until amino acid Ile1668, retaining the thrombin and Xa cleavage sites at position Arg 1689 and the putative von Willebrand factor (VWF) binding site between Val1670 and Arg1689. This 4.3-kb B-domain-deleted FVIII was reported to have the same activity as plasma-derived FVIII. ${ }^{19}$ The 4.4-kb canine B-domain-deleted FVIII cDNA sequence has been described previously. ${ }^{20}$

\section{Vector construction}

The HC-Ad vectors Ad-AAT-cFVIII, Ad-AAT-hFVIII, and Ad-Apo-cFVIII were constructed as infectious plasmids ( $p A d-A A T-c F V I I I, p A d-A A T-$ $h F V I I I$, and $p A d-A p o-c F V I I I)$. Schematic structures of the different HC-Ad vectors are shown in Figure 1. Details about the cloning procedure can be obtained on request. The Ad-AAT-cFVIII vector contains the Ad5 left terminus (nt 1-440), a 12-kb genomic fragment from the human $\alpha 1$ antitrypsin (AAT) locus (embedding the liver and macrophage-specific promoter, the first $A A T$ exon and intron, and the splice acceptor of the second exon), the canine FVIII cDNA (B-domain-deleted), $\beta$-globin poly $A$, hypoxanthine phosphoribosyltransferase (HPRT) stuffer (nt 1785514588, nt 8563-1799), and the $A d 5$ right terminus (nt 35818-35935) (Figure 1A). The Ad-AAT-hFVIII vector is comparable to that of Ad-AAT-cFVIII but contains the human (B-domain-deleted) FVIII cDNA instead. The Ad-Apo-cFVIII vector contains the Ad5 left terminus, HPRT stuffer (nt 1799-21729), SV40 poly A, the canine FVIII cDNA (B-domain-deleted), the chimeric ApoE-ApoCII promoter (Apo), C346 stuffer (nt 13143-16750), and the $A d 5$ right terminus. The $A A T$ promoter corresponds to nt 1-7316 and
A canine FVIII $\Delta B$

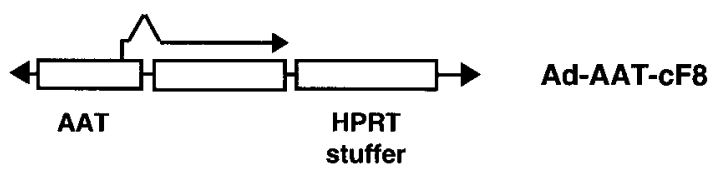

B human FVIIIAB
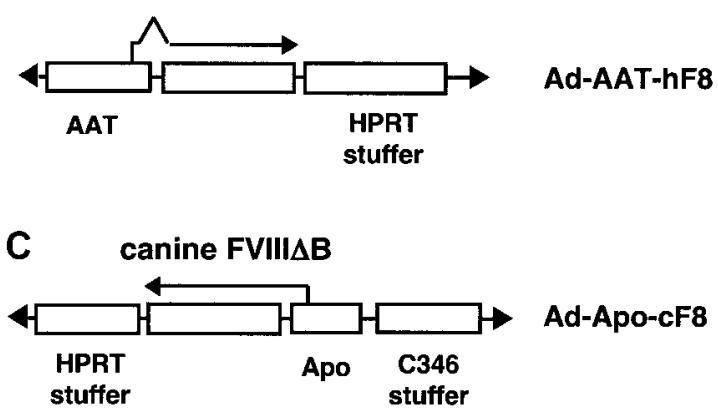

Figure 1. Design of HC-Ad vectors. (A-B) The Ad-AAT-cFVIII and Ad-AAT-hFVIII vectors carry the human $\alpha 1$-antitrypsin promoter (AAT) to direct the expression of the canine or human B-domain-deleted FVIII cDNA, respectively. An HPRT stuffer fragment was used to optimize vector size and to avoid vector rearrangements. $(C)$ In the Ad-Apo-cFVIII vector, the B-domain-deleted FVIII cDNA was expressed from the hepatocyte-specific chimeric $A p o E / A p o C l l$ promoter (Apo). An additional stuffer sequence derived from the $C 346$ cosmid fragment was used in the Ad-Apo-cFVIII vector.

a 5-kb upstream sequence derived from phage clone $\alpha \mathrm{NN}$ containing the human $A A T$ (hAAT) gene locus. ${ }^{21}$ The nucleotides refer to the sequences listed in GenBank. The ApoE enhancer and the ApoCII promoter were previously described. ${ }^{22,23}$

\section{Rescue of HC-Ad vectors}

Plasmids pAd-AAT-cFVIII, pAd-AAT-hFVIII, and pAd-Apo-cFVIII were digested with $P m e I$ flanking the adenoviral termini, phenol/chloroform extracted, and precipitated with ethanol. Two micrograms each plasmid were transfected into 293-based Cre66 cells (G.S. et al, manuscript in preparation), which were coinfected with the loxP helper virus AdLC8cluc. ${ }^{17}$ Subsequent amplification steps and large-scale preparation were performed as described previously. ${ }^{7}$ All vector preparations were purified twice by $\mathrm{CsCl}$ equilibrium density centrifugation, and the particle titers were evaluated by optical density measurements.

\section{Animal studies}

FVIII-deficient mice containing a disruption of the murine FVIII gene ${ }^{24}$ were bred to generate homozygous FVIII-deficient females and hemizygous FVIII-deficient males (designated as FVIIIKO). FVIIIKO mice were originally in a 129SV background backcrossed onto a C57B1/6 background. To obtain immunodeficient hemophilic mice (designated as FVIIIKOSCID), FVIII-deficient mice were crossed with SCID mice. ${ }^{25}$ These SCID mice are characterized by severe combined immune deficiency and are unable to mount a specific immune response to foreign antigens because of the lack of functional $\mathrm{T}$ and B cells. Genotyping and phenotypic characterization of the FVIIIKO and FVIIIKO-SCID offspring were performed as described, ${ }^{24}$ confirming that all FVIII-deficient mice used in this study contained the disrupted murine $F V I I I$ gene.

Two- to 3-month-old FVIIIKO or FVIIIKO-SCID mice were injected intravenously through the tail vein with the Ad-AAT-cFVIII, Ad-AAThFVIII, or Ad-Apo-cFVIII HC-Ad vector constructs at a dose of $5 \times 10^{9}$ infectious units (IU) per mouse. A dose-response study was performed with the Ad-AAT-cFVIII vector at doses of $5 \times 10^{9}, 10^{9}, 5 \times 10^{8}, 10^{8}, 5 \times 10^{7}$, and $5 \times 10^{6}$ IU per mouse. Similarly, FVIII-deficient littermates were injected with phosphate-buffered saline (PBS) as a control. Plasma samples were obtained from each mouse by retro-orbital bleeding in $20 \% 0.1 \mathrm{M}$ sodium citrate. Mouse experiments were approved by the Animal Ethical Commission of the University of Leuven. A total vector dose of $5.6 \times 10^{10}$ IU Ad-Apo-cFVIII, corresponding to $4.3 \times 10^{9} \mathrm{IU} / \mathrm{kg}$, was administered 
through an in-dwelling cephalic vein catheter into a 6-year-old, mixedbreed dog with severe hemophilia A (body weight, $13 \mathrm{~kg}$ ). ${ }^{26}$ The hemophilia dog was housed in facilities accredited by the Canadian Council for Animal Care, and experimental procedures were approved by the Queen's University Animal Care Committee.

\section{Analysis of FVIII production and anti-FVIII antibodies}

Biologically active human and canine FVIII was quantified in citratecontaining plasma samples from FVIIIKO or FVIIIKO-SCID mice by using FVIII COAtests (Chromogenix, Molndal, Sweden). ${ }^{27}$ FVIII levels in the dog plasma were determined using the COAmatic assay (Chromogenix) with a human reference plasma as the standard. Plasma from FVIIIKO or FVIIIKO-SCID mice spiked with human plasma-derived FVIII (Octapharma, Langenfeld, Germany) of known activity was used as standard. One unit corresponded to $200 \mathrm{ng}$ FVIII $/ \mathrm{mL}(100 \%=1000 \mathrm{mU})$. The sensitivity levels of the assay were less than $30 \mathrm{mU} / \mathrm{mL}$ and less than 5 $\mathrm{mU} / \mathrm{mL}$ on diluted mouse and canine plasma, respectively. Physiologic FVIII concentrations were defined as $200 \mathrm{ng} / \mathrm{mL}$. To further assess phenotypic correction of the clotting deficiency, plasma samples were subjected to a functional clotting assay (aPTT) that measures the activated partial thromboplastin time (SythASil APTT Reagent; Hemoliance, Lexington, MA). The whole blood clotting time in the hemophilia dog was measured following standard procedures. Inhibitory antibody titers in mice and in the dog were determined with Bethesda assays as described. ${ }^{28}$

\section{Macrophage depletion study}

Transient depletion of macrophages in livers and spleens of FVIIIKO and FVIIIKO-SCID mice was performed by intravenous injection of $0.2 \mathrm{~mL}$ clodronate-containing liposomes ${ }^{29} 24$ hours before injection of different doses of Ad-AAT-cFVIII vector, ranging from $10^{8}$ IU to $5 \times 10^{6} \mathrm{IU}$. Clodronate was a gift of Roche Diagnostics GmbH (Mannheim, Germany). Phosphatidylcholine (Lipoid E PC) (Lipoid GmbH, Ludwigshafen, Germany) and cholesterol (Sigma, St Louis, MO) were used to prepare the liposomes. Littermates were injected with liposomes containing PBS and used as controls. To confirm the effectiveness of macrophage depletion, some mice were killed, and single-cell suspensions were prepared from livers and spleens that were subsequently analyzed by flow cytometry (FACScalibur, equipped with CellQuest software; Becton Dickinson, Sunnyvale, CA) using phycoerythrin (PE)-conjugated macrophage-specific antibodies including anti-major histocompatibility complex (anti-MHC) class 2 antibodies (BD PharMingen, Erembodegem, Belgium) and antibodies specific for the F4/80 macrophage marker (Serotec, Düsseldorf, Germany). Appropriate isotypematched control antibodies were included in the fluorescence cell sorter (FACS) analysis.

\section{Analysis of vector DNA and RNA in vivo}

FVIIIKO mice were injected with $5 \times 10^{9}$ IU Ad-AAT-hFVIII. Genomic DNA from different organs was extracted by phenol/chloroform extraction as described previously. ${ }^{30}$ Polymerase chain reaction (PCR) with human FVIII-specific primers 5'-CCATATAACATCTACCCTCA-3' and $5^{\prime}$ GTTTCTCCTGAGAATGGGAA-3') was used to detect HC-Ad FVIII DNA. PCR was performed using PlatinumTaq (Invitrogen, Merelbeke, Belgium) by denaturing for 2 minutes at $94^{\circ} \mathrm{C}$, followed by 30 cycles of 30 seconds at $94^{\circ} \mathrm{C}, 30$ seconds at $55^{\circ} \mathrm{C}, 1$ minute at $72^{\circ} \mathrm{C}$ ), yielding a $0.6-\mathrm{kb}$ fragment. ${ }^{30} \mathrm{~A}$ retrovirally transduced vector producer cell line with a known number of human FVIII gene copies served as the standard ${ }^{30,31}$ for comparison. For normalization, PCR with $\beta$-actin-specific primers was performed as described previously ${ }^{30}$ yielding a $0.2-\mathrm{kb}$ fragment. Reverse transcription-PCR (RT-PCR) was performed as described previously, ${ }^{30}$ and the PCR conditions and primers were identical to those mentioned.

\section{Toxicity studies}

Measurements of serum alanine aminotransferase (ALT) and aspartate aminotransferase (AST) levels were performed on a Modular System (Roche/Hitachi) according to the manufacturer's instructions. Plasma samples were obtained from FVIIIKO-SCID mice $(n=3)$ injected with
$5 \times 10^{9} \mathrm{IU}$ Ad-AAT-cFVIII, Ad-AAT-hFVIII, and Ad-Apo-cFVIII vectors or in FVIIIKO mice $(\mathrm{n}=3)$ injected with $5 \times 10^{9}$ IU Ad-AAT-cFVIII. Plasma levels of the proinflammatory cytokine interleukin-6 (IL-6) were determined after injection of $5 \times 10^{9}$ IU Ad-AAT-cFVIII, Ad-AAT-hFVIII, and Ad-Apo-cFVIII vectors into FVIIIKO mice using sandwich enzymelinked immunosorbent assay (ELISA) (Quantikine; R\&D Systems, Minneapolis, MN). Platelet and red blood cell counts in FVIIIKO mice injected with $5 \times 10^{9}$ IU Ad-AAT-cFVIII, Ad-AAT-hFVIII, and Ad-Apo-cFVIII vectors were measured in whole blood containing 10\% EDTA (ethylenediaminetetraacetic acid) using a Cell-dyn 1300 blood counter (Abbott, IL). Toxicity assessment in the hemophilic dog was determined by measurement of serum ALT, AST, alkaline phosphatase (ALK P), bilirubin (Bili), urea, creatinine (Creat), creatinine kinase (CK), albumin (Alb), and iron levels according to standard procedures. ${ }^{15}$ Hematologic analysis was performed by quantifying platelets, red blood cells (RBCs), white blood cells (WBCs), hemoglobin $(\mathrm{Hg})$, and mean corpuscular volume (MCV) according to standard procedures, along with fibrinogen (FGN) and fibrinogendegradation products (FDPs). ${ }^{15}$

\section{Results}

\section{Generation of HC-Ad vectors}

Three HC-Ad vectors were compared in the present study (Figure 1). The Ad-AAT-cFVIII and Ad-AAT-hFVIII vectors express the canine or human B-domain-deleted FVIII cDNA, respectively, from the human $\alpha 1$-antitrypsin promoter (AAT) (Figure 1A-B). An $H P R T$ stuffer fragment was used to optimize vector size for packaging and to avoid vector rearrangements. ${ }^{32}$

The rationale for using the $A A T$ promoter was based on previous studies indicating that this promoter can lead to long-term, liver-specific expression of therapeutic proteins following transduction with $\mathrm{HC}$-Ad vectors into immunocompetent mice and baboons. ${ }^{7,33,34}$ In an alternative vector design (Ad-Apo-cFVIII), the canine B-domain-deleted FVIII cDNA was under control of the hepatocyte-specific chimeric ApoE/ApoCII promoter (Apo). In this vector an additional fragment from the $\mathrm{C} 346$ cosmid was included (Figure 1C). Average particle titers obtained with the Cre66 packaging cell line were comparable for the different vectors: $9.2 \times 10^{11}$ particles $/ \mathrm{mL}$ for Ad-AAT-cFVIII, $9.3 \times 10^{11}$ particles $/ \mathrm{mL}$ for Ad-AAT-hFVIII, and $8.4 \times 10^{11}$ particles $/ \mathrm{mL}$ for Ad-Apo-cFVIII. Average infectious titers, as determined by slot blot analyses, ${ }^{55}$ were $2.8 \times 10^{10} \mathrm{IU} / \mathrm{mL}$ for Ad-AAT-cFVIII, $2.7 \times 10^{10} \mathrm{IU} / \mathrm{mL}$ for Ad-AAT-hFVIII, and $1 \times 10^{10} \mathrm{IU} / \mathrm{mL}$ for Ad-Apo-cFVIII. DNAs from CsCl-purified vectors were analyzed by restriction digestion and did not show any rearrangements.

\section{HC-Ad-mediated FVIII gene delivery in immunodeficient hemophilic mice}

Adult hemophilic FVIIIKO-SCID mice were intravenously injected with the Ad-AAT-cFVIII vector at doses of $5 \times 10^{9} \mathrm{IU}, 10^{9}$ $\mathrm{IU}, 5 \times 10^{8} \mathrm{IU}, 10^{8} \mathrm{IU}, 5 \times 10^{7} \mathrm{IU}$ (Figure $2 \mathrm{~A}-\mathrm{E}$ ), and $5 \times 10^{6} \mathrm{IU}$. FVIII-deficient littermates were injected with PBS as control. Immunodeficient hemophilic mice were chosen to assess the long-term expression potential of this nonintegrating vector type in the absence of confounding immune responses against the human or canine FVIII xenoproteins. FVIII production in the plasma of recipient mice was determined using a functional FVIII chromogenic assay.

FVIII expression levels were dose dependent, with the 3 highest doses showing supraphysiologic FVIII levels (greater than 1000 $\mathrm{mU} / \mathrm{mL}$ ) (Figure 2). At the highest vector dose $\left(5 \times 10^{9} \mathrm{IU}\right)$ supraphysiologic canine FVIII levels were achieved for at least 6 months, stabilizing above the $15000 \mathrm{mU} / \mathrm{mL}$ level (Figure 2A). These 
A
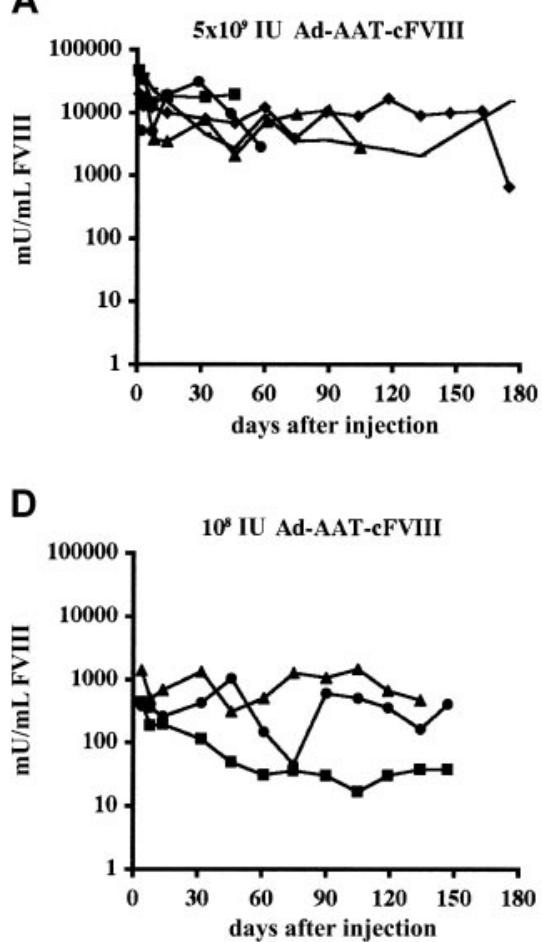

B

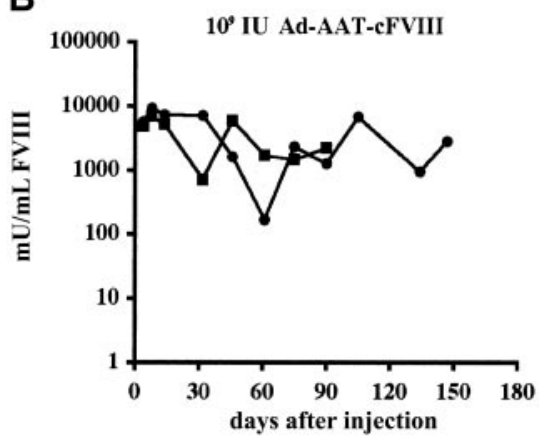

E

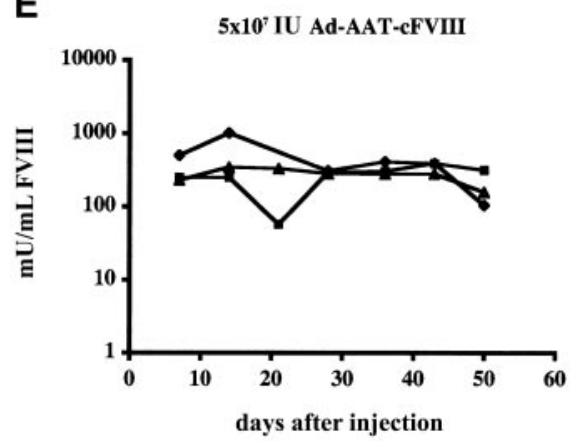

C

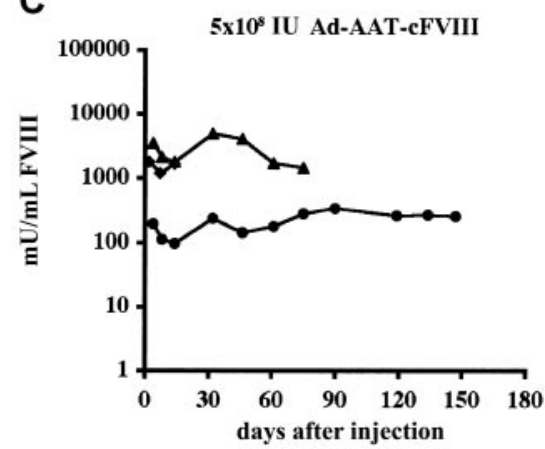

$\mathbf{F}$

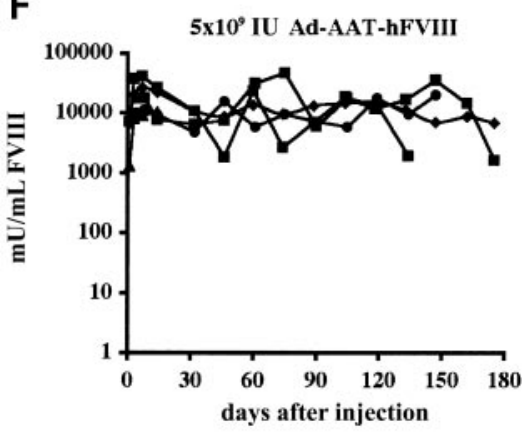

Figure 2. Functional FVIII expression kinetics in adult hemophilic FVIIIKO-SCID mice following HC-Ad gene transfer. Mice were injected intravenously with Ad-AAT-cFVIII at a dose of $5 \times 10^{9}(\mathrm{~A}), 10^{9}(\mathrm{~B}), 5 \times 10^{8}(\mathrm{C}), 10^{8} \mathrm{IU}(\mathrm{D})$, and $5 \times 10^{7} \mathrm{IU}(\mathrm{E})$ or with Ad-AAT-hFVIII at a dose of $5 \times 10^{9} \mathrm{IU}(\mathrm{F})$. FVIII-deficient littermates were injected with PBS as control.

levels are at least 15-fold higher than the FVIII concentration in healthy human plasma. Peak FVIII production levels corresponding to nearly $50000 \mathrm{mU} / \mathrm{mL}$ were observed. Even at a 100 -fold lower vector dose $\left(5 \times 10^{7} \mathrm{IU}\right)$ (Figure 2E), therapeutic FVIII concentrations were still observed in all recipient mice (ie, $100-1000 \mathrm{mU} / \mathrm{mL}$ ). No FVIII expression (less than $30 \mathrm{mU} / \mathrm{mL}$ ) could be detected after injecting $5 \times 10^{6}$ IU Ad-AAT-cFVIII. Control animals injected with PBS had no detectable FVIII activity (less than $30 \mathrm{mU} / \mathrm{mL}$ ).

In parallel, adult hemophilic FVIIIKO-SCID mice were intravenously injected with $5 \times 10^{9} \mathrm{IU}$ of Ad-AAT-hFVIII $(\mathrm{n}=5)$ (Figure 2F). Supraphysiologic human FVIII levels (exceeding 15000 $\mathrm{mU} / \mathrm{mL}$ ) were obtained for at least 6 months, consistent with the results obtained with the Ad-AAT-cFVIII vector. Similarly, longterm expression of supraphysiologic human or canine FVIII levels were achieved in NOD-SCID mice (data not shown).

To further assess phenotypic correction of the clotting deficiency, plasma samples were subjected to a functional clotting assay (aPTT) that measures the activated partial thromboplastin time. Clotting times were significantly reduced $(t$ test, $P<.001)$ in plasma obtained from hemophilic FVIIIKO-SCID mice that were injected with $5 \times 10^{9}$ IU Ad-AAT-cFVIII ( $22 \pm 8$ seconds) and Ad-AAT-hFVIII vectors ( $40 \pm 7$ seconds) compared with the clotting time of plasma from untreated hemophilic FVIIIKO-SCID mice (90 \pm 10 seconds) $(n=3)$. The clotting time of plasma from hemophilic animals injected with the FVIII vectors was similar or even lower than that of plasma from nonhemophilic mice $(40 \pm 4$ seconds). Hence, gene therapy using HC-Ad vectors stably corrected the bleeding diathesis of these hemophilic mice.

\section{HC-Ad-mediated FVIII gene delivery in immunocompetent hemophilic mice}

To evaluate FVIII expression kinetics in immunocompetent animals, adult hemophilic FVIIIKO mice were intravenously injected with Ad-AAT-cFVIII and Ad-AAT-hFVIII at a dose of $5 \times 10^{9} \mathrm{IU}$ ( $\mathrm{n}=6$ for each vector). FVIII peak expression levels were observed within 5 to 8 days after injection (Figure 3A-B). These peak levels corresponded to $50000 \mathrm{mU} / \mathrm{mL}$ for Ad-AAT-cFVIII and $75000 \mathrm{mU} / \mathrm{mL}$ for Ad-AAT-hFVIII. FVIII levels had fallen to baseline 3 to 4 weeks after injection. This decrease in FVIII expression coincided with the induction of neutralizing antibodies directed against the xenogeneic FVIII protein $(2-20 \mathrm{BU} / \mathrm{mL})$.

\section{Comparison of ApoE/ApoCII hepatocyte-specific promoter with AAT promoter}

Previous studies had suggested that the inadvertent expression of transgenes in antigen-presenting cells might lead to the formation of neutralizing antibodies against the transgene product. ${ }^{35}$ Because the AAT promoter is likely active in macrophagelike cells, possibly including Kupffer cells, ${ }^{7}$ it was important to rule out that the formation of neutralizing antibodies is attributed to the use of the AAT promoter that controls FVIII expression. An alternative HC-Ad was therefore evaluated that drives the canine B-domaindeleted FVIII gene from a chimeric ApoE/ApoCII hepatocytespecific promoter (Ad-Apo-cFVIII). Intravenous injection of FVIIIKO mice with $5 \times 10^{9}$ IU Ad-Apo-cFVIII led to a supraphysiologic FVIII plasma concentration (up to $40000 \mathrm{mU} / \mathrm{mL}$ ) approximately 5 to 8 days after injection (Figure 3C). Within 3 to 4 weeks after injection, expression declined to basal levels resembling the FVIII expression kinetics of the Ad-AAT-cFVIII and Ad-AAThFVIII vectors. This decline correlated with the induction of neutralizing antibodies against canine FVIII (4 BU/mL). Thus, the decline in human or canine FVIII expression in FVIIIKO mice was not inherent in the use of the AAT promoter.

After the injection of Ad-Apo-cFVIII into FVIIIKO-SCID (Figure 2) and NOD-SCID mice (data not shown), continuous FVIII expression (longer than 3 months) in the supraphysiologic range (exceeding 15000 
A

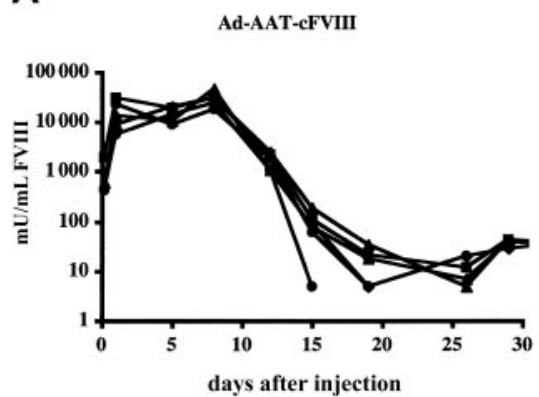

B

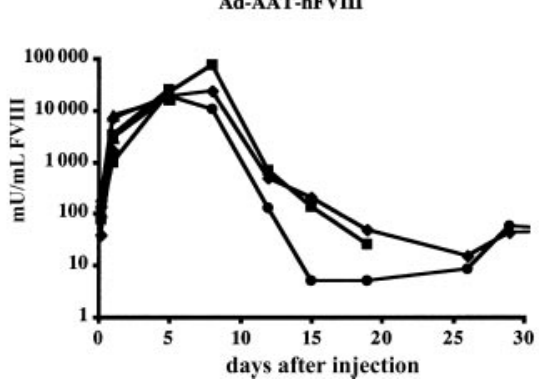

C

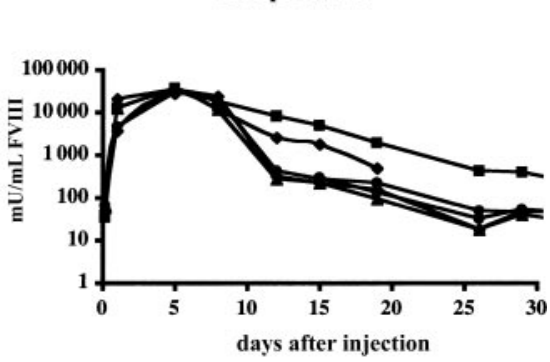

Figure 3. Functional FVIII expression kinetics in adult hemophilic FVIIIKO mice following HC-Ad gene transfer. Mice were injected intravenously with Ad-AAT-cFVIII (A), Ad-AAT-hFVIII (B), and Ad-Apo-cFVIII (C) at $5 \times 10^{9} \mathrm{IU}$ per mouse $(\mathrm{n}=6$ for each vector).

$\mathrm{mU} / \mathrm{mL}$ ) was observed, consistent with the expression profiles of Ad-AAT-cFVIII and Ad-AAT-hFVIII. Gene therapy using the Ad-ApocFVIII vector stably corrected the bleeding diathesis of these hemophilic mice. The clotting time based on aPTT assays was significantly reduced ( $t$ test, $P<.001$ ) in plasma obtained from hemophilic FVIIIKO-SCID mice injected with $5 \times 10^{9}$ IU Ad-Apo-cFVIII ( $27 \pm 5$ seconds) compared with that of plasma from untreated hemophilic FVIIIKOSCID mice (90 \pm 10 seconds) $(n=3)$.

Effect of transient macrophage depletion on FVIII expression in FVIIIKO and FVIIIKO-SCID mice transduced with HC-Ad vectors

The influence of cells of the innate immune system with regard to gene transfer efficiency using HC-Ad vectors has not been investigated. Therefore, the effect of transient depletion of tissue macrophages by clodronate liposome injection on FVIII expression was evaluated in FVIIIKO and FVIIIKO-SCID mice. Littermates were injected with PBS-containing liposomes as controls. Injection
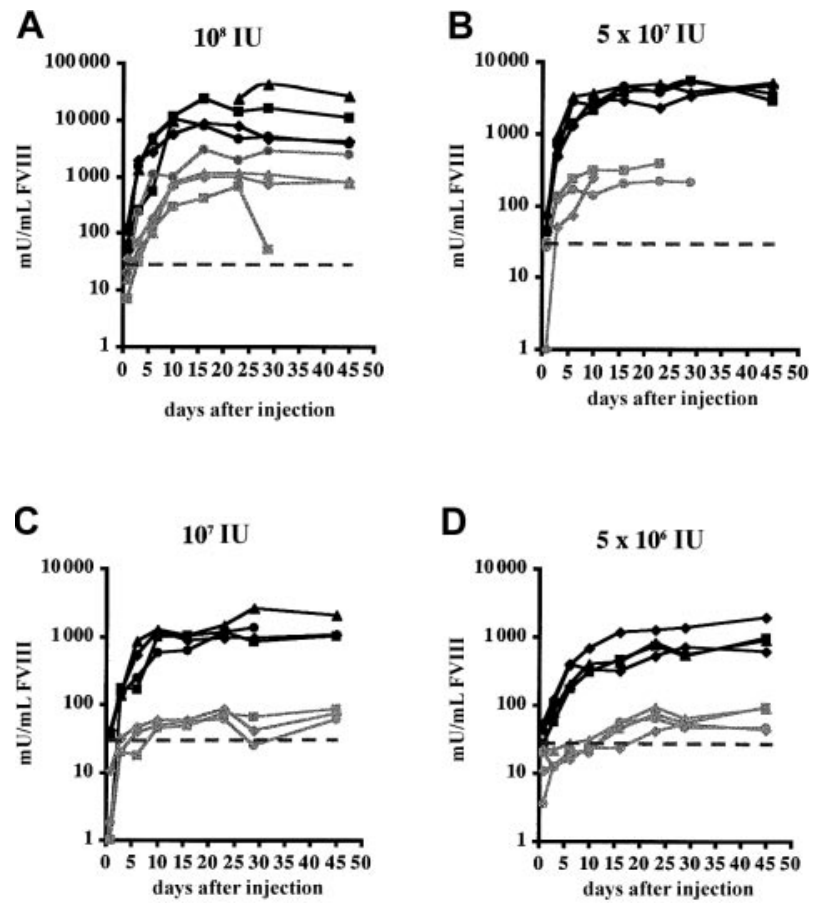

Figure 4. Functional FVIII expression in FVIIIKO-SCID mice following transient macrophage depletion. Experimental mice were injected with clodronate liposomes (black lines) 1 day before injection with Ad-AAT-cFVIII at different doses: $10^{8}(\mathrm{~A})$, $5 \times 10^{7}(B), 10^{7}(C)$, and $5 \times 10^{6} \mathrm{IU}(\mathrm{D})$. Littermates were injected with PBS containing liposomes as controls (gray lines). The detection limit of the assay corresponds to $30 \mathrm{mU} / \mathrm{mL}$ and was indicated on the graph by a dotted line. of liposomes containing clodronate resulted in a significant decrease in liver and spleen macrophages compared with controls, as confirmed by cytofluorometric analysis using macrophage-specific markers (MHC class II and F4/80) (data not shown). One day after liposome injection FVIIIKO-SCID and FVIIIKO mice were injected with Ad-AAT-cFVIII at doses of $5 \times 10^{9}, 10^{8}, 5 \times 10^{7}, 10^{7}$, and $5 \times 10^{6} \mathrm{IU}$ (Figures 4-5).

In FVIIIKO-SCID mice, treatment with clodronate liposomes resulted in a 10-fold increase of FVIII expression (Figure 4). Consequently, physiologic FVIII levels $(1000 \mathrm{mU} / \mathrm{mL})$ could still be achieved in the FVIIIKO-SCID mice using the lowest vector
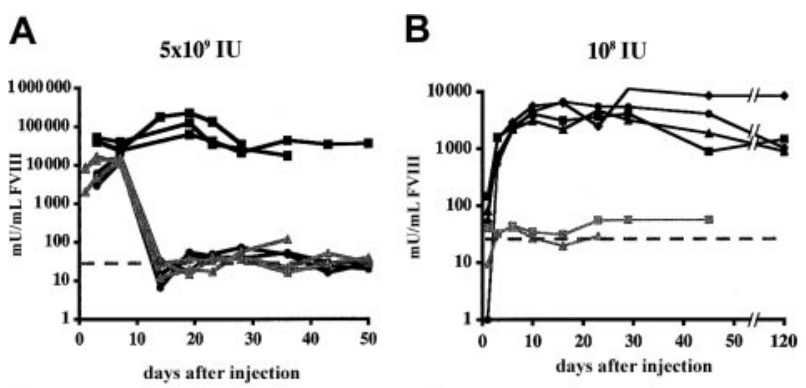

C
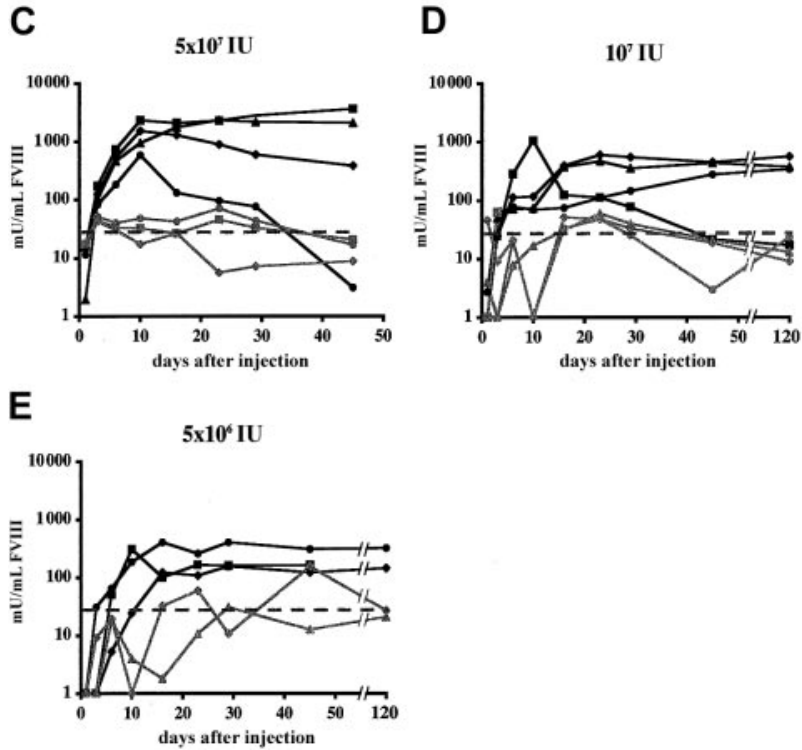

Figure 5. Functional FVIII expression in FVIIIKO mice following transient macrophage depletion. Mice were treated with clodronate liposomes (black lines) 1 day before the injection of Ad-AAT-cFVIII vectors at different doses: $5 \times 10^{9}(\mathrm{~A}), 10^{8}$ (B), $5 \times 10^{7}(\mathrm{C}), 10^{7}(\mathrm{D})$, and $5 \times 10^{6} \mathrm{IU}(\mathrm{E})$. Littermates were injected with PBS-containing liposomes as controls. Littermates were injected with PBScontaining liposomes as controls (gray lines). The detection limit of the assay corresponds to $30 \mathrm{mU} / \mathrm{mL}$ and was indicated on the graph by a dotted line. 
dose $\left(5 \times 10^{6} \mathrm{IU}\right)$, whereas FVIII production was near background levels in FVIIIKO-SCID mice injected with PBS liposomes (Figure 4C-D). FVIII expression was stable in FVIIIKO-SCID mice treated with either clodronate or PBS liposomes, consistent with the results presented in Figure 2.

In clodronate-liposome-treated FVIIIKO animals, dose-dependent and significantly increased FVIII expression levels were observed after Ad-AAT-cFVIII injection (Figure 5). This is consistent with the results obtained in FVIIIKO-SCID mice (Figure 4). Supraphysiologic and relatively stable FVIII levels exceeding $10000 \mathrm{mU} / \mathrm{mL}$ were achieved that lasted for at least 8 weeks, following the administration of $5 \times 10^{9}$ IU Ad-AAT-cFVIII in clodronate liposome-treated FVIIIKO mice. This was in contrast to the lower FVIII peak levels and the short-term FVIII expression in control FVIIIKO mice that received either PBS or PBS liposomes before injection with $5 \times 10^{9} \mathrm{IU}$ Ad-AAT-cFVIII. The lower FVIII expression levels and the limited duration of FVIII expression correlated with the induction of neutralizing antibodies to cFVIII, as confirmed in Bethesda assays (7-17 BU/mL). Similarly, at lower vector doses, FVIII expression was higher and more lasting in the FVIIIKO mice that received the clodronate liposomes than in PBS liposome-treated controls. FVIII expression was near background levels (less than $30 \mathrm{mU} / \mathrm{mL}$ ) in these animals (Figure 5B-E), which again correlated with the induction of neutralizing antibodies to cFVIII (10-20 BU/mL). The salutary effect of clodronate is long-lasting (longer than 6 months) in most recipient mice. In those few mice that showed a decline in FVIII expression, neutralizing antibodies to FVIII could be detected (2-11 BU/mL). Hence, a dual effect of clodronate-liposome treatment was apparent in FVIIIKO mice: not only was increased FVIII production observed, significantly prolonged FVIII gene expression was also observed.

\section{Biodistribution, transduction efficiency, and specificity of FVIII expression following $\mathrm{HC}$-Ad-mediated FVIII vector administration}

Biodistribution and gene transfer efficiency of HC-Ad vectors was determined in FVIIIKO mice injected with $5 \times 10^{9}$ IU Ad-AAThFVIII. Semiquantitative PCR using human FVIII-specific primers indicated that gene transfer occurred predominantly into liver, spleen, lungs, and heart. Vector-specific PCR fragments were not detected in testis, gut, brain, or kidney (Figure 6A-B). Gene transfer was more efficient in the liver than in any other organ. In addition, gene transfer in the spleen was more efficient than in the heart and lungs $(n=3)$. Five days after injection, there were more transduced cells in the livers and spleens of recipient FVIIIKO mice than at a later time point (1 month after injection; Figure 6A-B). As expected, human FVIII gene-specific bands were not detectable in control animals injected with PBS.

To evaluate which transduced tissue expressed FVIII mRNA, semiquantitative RT-PCR analysis was performed using human FVIII-specific primers. Human FVIII mRNA expression was detected in the liver but not in the other transduced organs-spleen (Figure 6C), lungs, or heart (data not shown). The apparent decrease of gene-marked cells in the liver (Figure 6A-B) correlated with a concomitant loss of hepatic human FVIII mRNA (Figure 6C). As expected, endogenous $\beta$-actin mRNA could be detected by RT-PCR in spleen and liver (Figure 6C), lungs, and heart tissue (data not shown) of experimental (Figure 6C) and negative control animals (data not shown).

\section{Safety assessment of HC-Ad vectors}

To evaluate potential hepatotoxicity associated with the use of HC-Ad vectors, liver transaminase levels (AST, ALT) ${ }^{36}$ were determined in the plasma at different intervals following injection of FVIIIKO-SCID mice with the highest dose of $5 \times 10^{9} \mathrm{IU}$ of the Ad-AAT-cFVIII, Ad-AAT-hFVIII, and Ad-Apo-cFVIII vectors (Figure 7A). Ad-AAT-hFVIII and Ad-Apo-cFVIII vector preparations did not lead to a significant increase $(P>.05)$ in AST or ALT level in the plasma, whereas a slight, yet significant $(P<.001), 3-$ to 4-fold increase in AST and ALT levels was apparent 1 day after Ad-AAT-cFVIII transduction compared with PBS-injected controls. Nevertheless, after a few days, AST and ALT levels returned to basal levels indistinguishable from normal physiologic levels. The exact reason for the differences among the different vector batches is unclear but might reflect differences in vector purity. Injection of $5 \times 10^{9} \mathrm{IU}$ Ad-AAT-cFVIII into FVIIIKO mice did not trigger any AST and ALT elevations during the first week after injection (Figure 7A). This confirms that direct hepatotoxicity of HC-Ad vector particles is limited or absent in this mouse model. However, at 2 weeks after injection, a transient yet significant increase in AST and ALT levels was apparent, consistent with the induction of a cellular immune response that eliminated the FVIII-transduced hepatocytes; this is in agreement with the PCR data (Figure 6).

Because the administration of early-generation adenoviral vectors is known to result in thrombocytopenia, ${ }^{37}$ platelet counts were performed in FVIIIKO mice that had received $5 \times 10^{9} \mathrm{IU}$
A

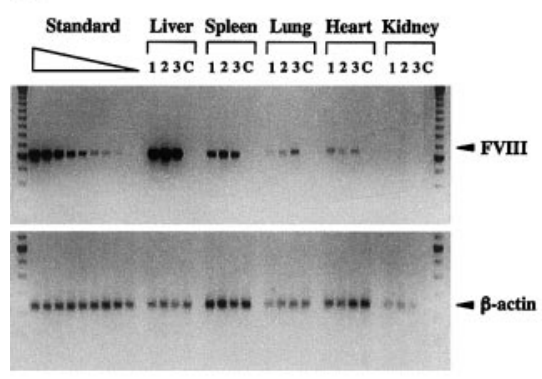

B

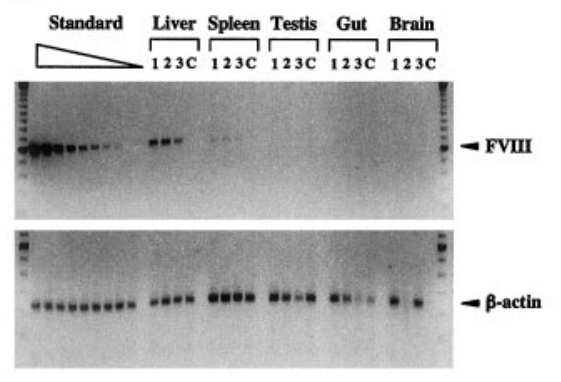

C

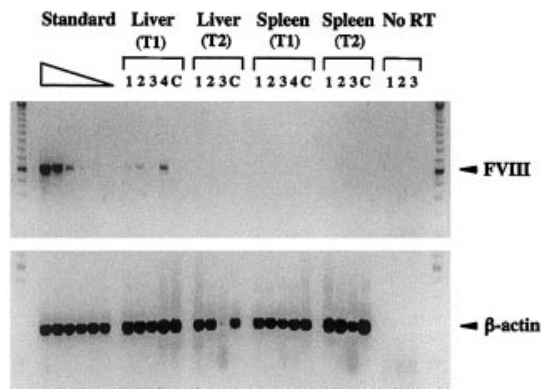

Figure 6. Biodistribution of HC-Ad vectors, gene transfer efficiency, and FVIII mRNA expression analysis. FVIIIKO mice were injected with $5 \times 10^{9}$ IU Ad-AAT-hFVIII. Semiquantitative PCR (A-B) or RT-PCR (C) using human FVIIl-specific and $\beta$-actin-specific primers $(\mathrm{n}=3$ mice) at an early time point (5 days after injection, T1) in liver, spleen, lung, heart, and kidney (A) and testis, gut, and brain (B). PCR analysis of liver and spleen at a late time point (1 month after injection, T2) is shown in (B). Mice injected with PBS were used as controls (C). For RT-PCR analysis, controls included samples without reverse transcriptase (no RT) to exclude genomic DNA contamination. Molecular weight (MW) marker was the 100-bp ladder. FVIII PCR generated a 0.6-kb fragment, and $\beta$-actin PCR generated a 0.2-kb fragment. Standard corresponds to 2-fold serially diluted DNA with a known number of FVIII copies (ranging from 4 to 0 FVIII gene copies per diploid genomic equivalent). 
A
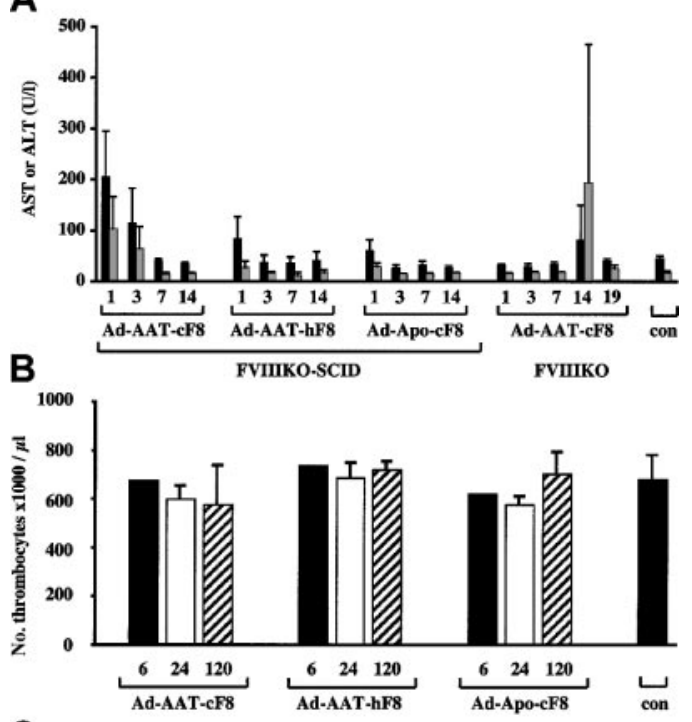

C

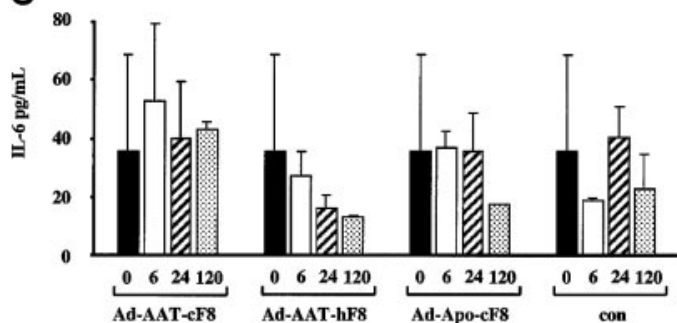

Figure 7. Toxicity analysis of HC-Ad vectors. AST (black bars) and ALT (gray bars) levels $(A)$ in plasma from FVIIIKO-SCID mice injected intravenously with $5 \times 10^{9} \mathrm{IU}$ Ad-AAT-cFVIII, Ad-AAT-hFVIII, and Ad-Apo-cFVIII. Alternatively, $5 \times 10^{9} \mathrm{IU}$ Ad-AATcFVIII was injected intravenously into FVIIIKO mice. (A) Platelet counts (B) and IL-6 levels $(C)$ in plasma from FVIIIKO-SCID mice intravenously injected with $5 \times 10^{9} \mathrm{IU}$ Ad-AAT-cFVIII, Ad-AAT-hFVIII, and Ad-Apo-cFVIII.

Ad-AAT-cFVIII, Ad-AAT-hFVIII, and Ad-Apo-cFVIII. No significant differences in platelet counts were observed in mice that received the different $\mathrm{HC}$-Ad vectors compared with PBS-injected FVIII-KO controls (Figure 7B). In addition, there was no evidence of anemia or erythroblastosis because erythrocyte counts were normal following $\mathrm{HC}$-Ad vector administration in FVIIIKO mice (data not shown).

Finally, it has been shown that early-generation adenoviral vectors trigger a rapid induction of proinflammatory cytokines, particularly IL-6, associated with an acute-phase inflammatory response that contributes to vector toxicity. ${ }^{38}$ To determine whether the vectors used in this study were associated with an increase in IL-6, FVIIIKO mice were injected with $5 \times 10^{9}$ IU Ad-AATcFVIII, Ad-AAT-hFVIII, and Ad-Apo-cFVIII (Figure 7C). As in control animals, there were no significant increases (one-way analysis of variance [ANOVA]; $P>.05$ ) in plasma IL-6 levels after injection of the various $\mathrm{HC}$-Ad vectors. In conclusion, these results underscore the relative safety of HC-Ad vectors for gene therapy of hemophilia A.

\section{HC-Ad-mediated FVIII gene delivery in a hemophilia A dog}

The Ad-Apo-cFVIII vector was injected into an adult dog with severe hemophilia A at a dose of $4.3 \times 10^{9} \mathrm{IU} / \mathrm{kg}$ or $3 \times 10^{11} \mathrm{vp} / \mathrm{kg}$ (total vector dose per dog, $5.6 \times 10^{10}$ IU or $4 \times 10^{12} \mathrm{vp}$; dog weight, $13 \mathrm{~kg}$ ). Transient therapeutic FVIII levels could be achieved to a maximum of $3.5 \%$ of normal human FVIII levels (35 $\mathrm{mU} / \mathrm{mL}$ ) at 3 days after injection (Figure 8), which correlated with a significant shortening of the whole blood clotting time (WBCT) from 14 minutes (baseline) to 8 minutes at 3 days after injection. Inhibitory antibodies to canine FVIII were absent, as confirmed by Bethesda assays. Most important, the HC-Ad vector was not associated with any detectable hepatotoxicity, nephrotoxicity (no significant changes in serum ALT, AST, ALKP, bilirubin, urea, creatinine, albumin, and iron levels, Table 1), or hematologic abnormalities (no significant changes in platelet, RBC, WBC, HMCT, Hg, or MCV counts; Table 1). In addition, we found no evidence of abnormal levels of FGN (Table 1) or FDP (Table 1).

\section{Discussion}

The present study showed that unprecedentedly high levels of human or canine B-domain-deleted factor VIII were produced in adult hemophilic mice following gene therapy with the latest generation HC-Ad vector technology. Peak FVIII levels of $7500 \%$ could be achieved in hemophilic animals using a vector dose $\left(5 \times 10^{9} \mathrm{IU} /\right.$ mouse $)$ that was relatively nontoxic in mice. In particular, the HC-Ad vectors used in the present study appear to be at least 20- to 40-fold better than those used in a previous study based on HC-Ad vectors using comparable vector doses. ${ }^{39}$ Most important, the injection of a relatively low vector dose $\left(10^{8}\right.$ IU/mouse) still resulted in physiologic FVIII levels using the present HC-Ad vector, whereas in previously published studies no FVIII levels could be detected at these low vector doses using an $\mathrm{HC}$-Ad vector currently in clinical trials. ${ }^{39}$ Furthermore, using the current HC-Ad vector design, therapeutic FVIII levels could still be obtained at a 100 -fold lower dose (ie, $5 \times 10^{7} \mathrm{IU}$ ). Hence, this level of improvement may have important consequences for clinical trials.

The use of HC-Ad vectors resulted in FVIII levels in mice that were 1000 - to 10000 -fold higher than the therapeutic threshold concentration of $1 \%$ needed to convert severe to moderate hemophilia. These levels are several orders of magnitude higher than the FVIII expression levels that could be achieved using current $\mathrm{AAV}^{40}$ (20\%-30\%) or lentiviral ${ }^{41}(10 \%-20 \%$, after partial hepatectomy only) vectors in adult mice. In addition, many previous studies reported a lack of FVIII or short-term FVIII expression following gene therapy in animal models. ${ }^{42,43}$ It is likely that the use of the HC-Ad vector technology and the optimization of the FVIII expression cassettes were responsible for the high FVIII levels unparalleled in any other study so far. This is consistent with the high factor IX levels that were recently obtained using HC-Ad vectors. ${ }^{56}$ The particular combination of FVIII transgenes, promoters, and stuffer fragments used in this study had not been tested previously. The use of the B-domain-deleted instead of the

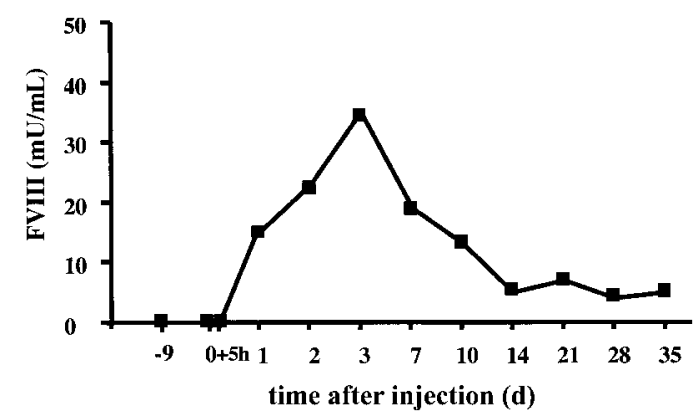

Figure 8. Functional FVIII expression kinetics in an adult hemophilia A dog following HC-Ad gene transfer. The dog was injected intravenously with $5.6 \times 10^{10}$ IU $\left(4 \times 10^{12}\right.$ vector particles [vp] $)$ Ad-Apo-cFVIII vector 
Table 1. HC-Ad safety evaluation in hemophilia A dog model

\begin{tabular}{|c|c|c|c|c|c|c|c|c|c|c|c|c|c|c|c|c|}
\hline & \multicolumn{8}{|c|}{ Serum chemistry values } & \multicolumn{8}{|c|}{ Hematology } \\
\hline & $\begin{array}{l}\mathrm{ALT}, \\
\mathrm{U} / \mathrm{L}\end{array}$ & $\begin{array}{c}\text { AST, } \\
\mathrm{U} / \mathrm{L}\end{array}$ & $\begin{array}{c}\text { ALK P, } \\
U / L\end{array}$ & $\begin{array}{l}\text { Bili, } \\
\mu \mathrm{M}\end{array}$ & $\begin{array}{c}\text { Urea, } \\
\mathrm{mM}\end{array}$ & $\begin{array}{c}\text { Creat, } \\
\mu \mathrm{M}\end{array}$ & $\begin{array}{l}\text { CK, } \\
\text { U/L }\end{array}$ & $\begin{array}{l}\text { Alb, } \\
\text { g/L }\end{array}$ & $\begin{array}{l}\text { Iron, } \\
\mu \mathrm{M}\end{array}$ & $\begin{array}{l}\text { Platelet, } \\
\times 10^{9} / \mathrm{L}\end{array}$ & $\begin{array}{c}\mathrm{RBC}, \\
\times 10^{12} / \mathrm{L}\end{array}$ & $\begin{array}{c}\text { WBC, } \\
\times 10^{9} / \mathrm{L}\end{array}$ & $\begin{array}{l}\mathrm{Hg}, \\
\mathrm{g} / \mathrm{L}\end{array}$ & $\begin{array}{c}M C V, \\
f L\end{array}$ & $\begin{array}{c}\text { FGN, } \\
\text { g/L }\end{array}$ & $\begin{array}{l}\text { FDP, } \\
\mathrm{ng} / \mathrm{mL}\end{array}$ \\
\hline Baseline & 54 & 28 & 56 & 3 & 4.9 & 49 & 244 & - & - & 304 & 7.7 & 10 & 180 & 67.6 & - & Normal \\
\hline Preinjection & 50 & 22 & 44 & 3 & 2.8 & 50 & 122 & 34 & 21 & 233 & 7.1 & 7.3 & 164 & 68.1 & 1.7 & Normal \\
\hline $5 \mathrm{~h}$ & 53 & 26 & 51 & 3 & 5.0 & 44 & 145 & 36 & 17 & 253 & 7.2 & 14.5 & 170 & 68.1 & 1.9 & Normal \\
\hline $1 d$ & 51 & 24 & 61 & 3 & 2.5 & 48 & 148 & 34 & 24 & 220 & 6.5 & 4.9 & 151 & 68.7 & 2.6 & Normal \\
\hline $2 d$ & 56 & 24 & 56 & 2 & 2.8 & 47 & 102 & 34 & 32 & 219 & 7.4 & 6.9 & 174 & 69.0 & 2.2 & Normal \\
\hline $3 d$ & 51 & 25 & 49 & 3 & 3.2 & 46 & 106 & 33 & 26 & 221 & 6.9 & 7.9 & 160 & 67.8 & 1.7 & Normal \\
\hline $7 d$ & 45 & 20 & 44 & 2 & 4.3 & 50 & 94 & 34 & 28 & 220 & 6.7 & 8.4 & 155 & 69.2 & 1.9 & Normal \\
\hline $10 \mathrm{~d}$ & 48 & 22 & 46 & 2 & 4.1 & 52 & 105 & 35 & 31 & 251 & 7.0 & 8.8 & 165 & 69.2 & 1.9 & Normal \\
\hline $14 d$ & 56 & 27 & 53 & - & 2.7 & 42 & 104 & 35 & 33 & 257 & 7.7 & 7.4 & 178 & 68.8 & 2.2 & Normal \\
\hline $21 d$ & - & - & - & - & - & - & - & - & - & - & - & - & - & - & 1.8 & Normal \\
\hline $28 d$ & 64 & 24 & 48 & - & 3.3 & 43 & 125 & 36 & 25 & 264 & 7.8 & 6.7 & 180 & 69.0 & 1.4 & Normal \\
\hline $35 \mathrm{~d}$ & - & - & - & - & - & - & - & - & - & - & - & - & - & - & - & - \\
\hline
\end{tabular}

— indicates not determined.

full-length FVIII cDNA might have boosted FVIII production because the B domain is known to suppress FVIII expression. ${ }^{44,45}$ The use of potent liver-specific promoters such as the chimeric ApoE enhancer/ApoCII promoter or the AAT promoter might have further contributed to these high FVIII expression levels. Finally, it is noteworthy that there was no apparent thrombotic toxicity associated with these extraordinarily high plasma FVIII levels.

The stable, long-term expression of supraphysiologic FVIII levels in FVIIIKO-SCID mice following HC-Ad-mediated gene delivery is consistent with previous reports. ${ }^{7,16,33,39,46}$ This prolonged transgene expression likely results from the lack of residual adenoviral gene expression, the reduced toxicity, and the reduced inflammatory properties of HC-Ad vectors compared with earlygeneration adenoviral vectors. ${ }^{15,36}$ In the present study, no thrombocytopenia, anemia, erythroblastosis, or elevation of proinflammatory cytokine IL-6 were apparent after HC-Ad vector administration in mice, which further underscores the relative safety of these improved adenoviral vectors in contrast to early-generation vectors. ${ }^{37}$ In addition, HC-Ad vector preparations triggered no or only limited and transient elevations in serum transaminases (AST and ALT). However, Wilson and colleagues ${ }^{47,48}$ have shown that mice are relatively resistant to toxicity from early-generation adenoviral vectors compared with nonhuman primates, which show significant morbidity and mortality at doses $\left(10^{13} \mathrm{vp} / \mathrm{kg}\right)$ comparable to those used in our present study. Similarly, mice injected with an early-generation adenoviral vector encoding FVIII displayed significantly fewer toxic effects than did hemophilia A dogs. ${ }^{15,18}$ In addition, one patient with ortinithine carbamyl transferase (OTC) deficiency recently died after intrahepatic artery injection of $6 \times 10^{11} \mathrm{vp} / \mathrm{kg}$ of an early-generation E1/E3/E4-deleted vector. ${ }^{49} \mathrm{It}$ appears therefore that there may be significant differences in adenoviral toxicity among species and perhaps also between individuals. This makes it particularly difficult to extrapolate safety data from mice to larger animal models or human patients. However, these adenoviral toxicity studies were performed largely using early-generation adenoviral vectors that, by virtue of the residual adenoviral gene expression, are more toxic and trigger more potent inflammatory responses than $\mathrm{HC}$-Ad vectors. The favorable safety profile of the HC-Ad vectors in the canine model, as shown in the present study, is therefore consistent with the safety profile in hemophilic mice and is in contrast to the toxicity of early-generation adenoviral vectors in large animal models, such as hemophilia A dogs or primates. ${ }^{15,50}$

Human and canine FVIII production was transient in immunocompetent FVIIIKO mice, in contrast to the long-term gene expression that was observed in immunodeficient hemophilic mice. Short-term FVIII expression in immunocompetent FVIIIKO mice was caused by an immune mechanism. This was confirmed by showing that neutralizing antibodies were induced that were associated with a decrease in FVIII expression. PCR analysis confirmed that FVIII-transduced cells disappeared over time (Figure 6), indicating that a cellular immune mechanism contributed to the loss of FVIII expression in FVIIIKO mice.

The induction of neutralizing antibodies against xenogenic FVIII proteins in mice has also been observed using HC-Ad vectors that express full-length human FVIII cDNA, ${ }^{39}$ though the onset was more rapid in the present study, perhaps because of higher FVIII expression levels. In addition, $\mathrm{AAV}, 40$ lentiviral, ${ }^{41}$ and retroviral ${ }^{30}$ vector-mediated $F$ VIII gene delivery also resulted in the induction of neutralizing antibodies against human FVIII. These results indicate that human (and canine) FVIII proteins are highly immunogenic xenoantigens in (hemophilic) mice. However, in some previous studies using adenoviral vectors, no FVIII-specific antibodies were detected, a finding that was explained by genetic influences of the mice strain used. ${ }^{11}$

Expression of canine FVIII is also transient in the hemophilia A dog model. In contrast to transient human or canine FVIII expression in immunocompetent hemophilic mice, the decline in transgene expression following HC-Ad gene transfer in the dog does not correlate with the induction of neutralizing antibodies to canine FVIII, as measured using Bethesda assays. Despite the fact that Bethesda assay findings were negative, it cannot be excluded that a nonneutralizing anti-FVIII antibody could have resulted in the accelerated clearance of FVIII. Antibodies from hemophilia A patients are frequently directed toward epitopes of FVIII that are not directly involved in the function of the molecule and therefore escape detection in the Bethesda method, ${ }^{51}$ but these nonneutralizing antibodies are sometimes associated with increased FVIII clearance from the circulation (K. Peerlinck, C. Van Geet, personal communication, August 2002). Alternatively, the decline in FVIII expression may reflect some loss of FVIII transgenes or a transcriptional effect. Morral et $\mathrm{al}^{33}$ recently demonstrated that the duration and level of transgene expression (ie, hAAT) is variable in baboons injected with HC-Ad vectors: hAAT transgene expression was short term in one of the baboons, which correlated with the presence of anti-hAAT antibodies, whereas in the other 2 baboons, no anti-hAAT antibodies could be detected and long-term hAAT expression could be achieved. Hence, it is possible that if more dogs are tested, some may show prolonged expression. Future 
studies in new cohorts will be necessary to further address these issues.

Limited information is available on the role of the innate immune system with regard to gene transfer using HC-Ad vectors. To evaluate the contribution of the innate immune system on HC-Ad vector, macrophages were eliminated using clodronate liposomes. Clodronate liposomes are being evaluated in clinical trials by local administration in patients to transiently eliminate tissue macrophages. ${ }^{52}$ The effects of clodronate liposomes typically last for a few days at the maximum. Given the fact that depleted resident macrophages are replaced by new ones, differentiating from bone marrow-derived monocytes, the transient nature of the depletion is obvious. After the depletion of Kupffer cells in the liver, new Kupffer cells start to reappear within 1 week, and the mice then become capable of mounting an immune response to other neoantigens. ${ }^{53}$

The present results demonstrate that the transient depletion of macrophages using clodronate liposomes resulted in increased FVIII production levels in FVIIIKO and FVIIIKO-SCID mice. Most important, significantly prolonged $F V I I I$ gene expression was achieved in these FVIIIKO mice, indicating that the innate immune compartment limits the therapeutic efficacy of HC-Ad vectors. This reduced therapeutic efficacy is likely the combined result of a direct uptake of HC-Ad vector particles by antigen-presenting cells in conjunction with the induction of a specific humoral immune response.

The present results clearly indicate that the therapeutic window of HC-Ad vectors could be improved further by minimizing the interaction between $\mathrm{HC}$-Ad vectors and the innate immune system. This proof-of-concept study justifies exploring alternative and clinically approved agents, such as gamma globulins, that act in a manner similar to that of clodronate liposomes ${ }^{54}$ Alternatively, the development of targeted HC-Ad vectors that selectively transduce hepatocytes while bypassing the innate immune compartment is warranted.

To our knowledge, no previous publications report the use of HC-Ad expressing an autologous canine FVIII transgene in dogs with hemophilia A. Transient therapeutic canine FVIII expression levels were obtained in the present study that partially corrected a bleeding diathesis in a dog with hemophilia A. Inhibitory antibodies to canine FVIII could not be detected, unlike when firstgeneration adenoviral vectors are used to deliver canine FVIII to hemophilia A dogs. ${ }^{15} \mathrm{HC}$-Ad vector was not associated with any detectable hepatotoxicity or nephrotoxicity or with hematologic abnormalities in the hemophilia A dog, consistent with the safety profile of HC-Ad in hemophilic mice but in contrast to the toxicity of first-generation adenoviral vectors in large animal models. ${ }^{15,50} \mathrm{In}$ addition, there was no evidence of a consumptive coagulation process, unlike when first-generation adenoviral vectors are used. ${ }^{50}$

The HC-Ad vector seems less efficacious in hemophilic dogs than in mice, based on FVIII expression levels, when comparable vector doses per kilogram are used (Table 1 vs Figure 2). It is therefore possible that the threshold dose is higher in dogs than in mice. This may reflect differences in receptor expression levels in dogs versus mice, which may influence the threshold effect. Other factors, including differences in vector biodistribution, may contribute to these differences between different species.

The present study contributes to a better understanding of the safety and efficacy of HC-Ad vectors in clinically relevant hemophilia animal models and suggests that the therapeutic window of HC-Ad vectors could be improved by minimizing the interaction between HC-Ad vectors and the innate immune system. This preclinical study has important implications for clinical trials based on HC-Ad vectors.

\section{Acknowledgments}

We thank Dr Kazazian (University of Pennsylvania) and Dr Saint-Remy (University of Leuven) for the FVIII-KO mice and immunodeficient FVIIIKO-SCID and Dr De Geest (University of Leuven) for providing us with the ApoE/ApoCII promoter. We also thank Mrs Vanslembrouck and Mrs Vangoidsenhoven for technical assistance, Dr Arnout and Mrs Van Russelt for their help with the aPTT assays, and Dr Vermylen (University of Leuven) for reviewing the manuscript.

\section{References}

1. Kaufman RJ. Advances toward gene therapy for hemophilia at the millennium. Hum Gene Ther. 1999;10:2091-2107.

2. Kay MA, High K. Gene therapy for the hemophilias [comment]. Proc Natl Acad Sci U S A. 1999;96:9973-9975

3. Chuah MK, Collen D, VandenDriessche T. Gene therapy for hemophilia: hopes and hurdles. Crit Rev Oncol Hematol. 1998;28:153-171.

4. Chuah MK, Collen D, VandenDriessche T. Gene therapy for hemophilia. J Gene Med. 2001; 3:3-20.

5. Yang Y, Su Q, Wilson JM. Role of viral antigens in destructive cellular immune responses to adenovirus vector-transduced cells in mouse lungs. J Virol. 1996;70:7209-7212.

6. Fang B, Wang H, Gordon G, et al. Lack of persis tence of E1-recombinant adenoviral vectors containing a temperature-sensitive E2A mutation in immunocompetent mice and hemophilia B dogs. Gene Ther. 1996;3:217-222.

7. Schiedner G, Morral N, Parks RJ, et al. Genomic DNA transfer with a high-capacity adenovirus vector results in improved in vivo gene expression and decreased toxicity [published erratum appears in Nat Genet. 1998;18:298]. Nat Genet. 1998;18:180-183

8. Yang Y, Ertl HC, Wilson JM. MHC class I- restricted cytotoxic T lymphocytes to viral antigens destroy hepatocytes in mice infected with E1-deleted recombinant adenoviruses. Immunity. 1994;1:433-442.

9. Yang Y, Li Q, Ertl HC, Wilson JM. Cellular and humoral immune responses to viral antigens create barriers to lung-directed gene therapy with recombinant adenoviruses. J Virol. 1995;69: 2004-2015

10. Yang Y, Jooss KU, Su Q, Ertl HC, Wilson JM. Immune responses to viral antigens versus trans gene product in the elimination of recombinant adenovirus-infected hepatocytes in vivo. Gene Ther. 1996;3:137-144

11. Connelly S, Smith TA, Dhir G, et al. In vivo gene delivery and expression of physiological levels of functional human factor VIII in mice. Hum Gene Ther. 1995;6:185-193.

12. Connelly S, Gardner JM, McClelland A, Kaleko M. High-level tissue-specific expression of functional human factor VIII in mice. Hum Gene Ther 1996;7:183-195.

13. Connelly S, Mount J, Mauser A, et al. Complete short-term correction of canine hemophilia A by in vivo gene therapy. Blood. 1996;88:3846-3853.

14. Connelly S, Andrews JL, Gallo AM, et al. Sustained phenotypic correction of murine hemo- philia A by in vivo gene therapy. Blood. 1998:91: 3273-3281.

15. Gallo-Penn AM, Shirley PS, Andrews JL, et al. Systemic delivery of an adenoviral vector encoding canine factor VIII results in short-term phenotypic correction, inhibitor development, and biphasic liver toxicity in hemophilia A dogs. Blood. 2001;97:107-113.

16. Kochanek S. High-capacity adenoviral vectors for gene transfer and somatic gene therapy. Hum Gene Ther. 1999;10:2451-2459.

17. Parks RJ, Chen L, Anton M, Sankar U, Rudnicki MA, Graham FL. A helper-dependent adenovirus vector system: removal of helper virus by Cremediated excision of the viral packaging signal. Proc Natl Acad Sci U S A. 1996;93:13565-13570.

18. Gallo-Penn AM, Shirley PS, Andrews JL, et al. In vivo evaluation of an adenoviral vector encoding canine factor VIII: high-level, sustained expression in hemophiliac mice. Hum Gene Ther. 1999; 10:1791-1802.

19. Mertens K, Donath MJ, van Leen RW, et al. Biological activity of recombinant factor VIII variants lacking the central B-domain and the heavy-chain sequence Lys713-Arg740: discordant in vitro and in vivo activity. Br J Haematol. 1993;85:133-142.

20. Cameron C, Notley C, Hoyle S, et al. The canine 
factor VIII cDNA and 5' flanking sequence. Thromb Haemost. 1998;79:317-322.

21. Dycaico MJ, Grant SG, Felts K, et al. Neonatal hepatitis induced by alpha 1-antitrypsin: a transgenic mouse model. Science. 1988;242:14091412.

22. Van Linthout S, Collen D, De Geest B. Effect of promoters and enhancers on expression, transgene DNA persistence, and hepatotoxicity after adenoviral gene transfer of human apolipoprotein a-I. Hum Gene Ther. 2002;13:829-840.

23. De Geest B, Van Linthout S, Collen D. Sustained expression of human apo A-I following adenovira gene transfer in mice. Gene Ther. 2001;8:121127.

24. Bi L, Lawler AM, Antonarakis SE, High KA, Gearhart JD, Kazazian HH Jr. Targeted disruption of the mouse factor VIII gene produces a model of haemophilia A [letter]. Nat Genet. 1995;10:119121.

25. Bosma GC, Custer RP, Bosma MJ. A severe combined immunodeficiency mutation in the mouse. Nature. 1983;301:527-530.

26. Giles AR, Tinlin S, Hoogendoorn H, Greenwood P, Greenwood R. Development of factor VIII:C antibodies in dogs with hemophilia A (factor VIII:C deficiency). Blood. 1984;63:451-456.

27. Chuah MK, Vandendriessche T, Morgan RA. Development and analysis of retroviral vectors expressing human factor VIII as a potential gene therapy for hemophilia A. Hum Gene Ther. 1995; 6:1363-1377.

28. Kasper CK, Aledort L, Aronson D, et al. Proceedings: a more uniform measurement of factor VIII inhibitors. Thromb Diath Haemorrh. 1975;34:612.

29. Van Rooijen N, Sanders A. Kupffer cell depletion by liposome-delivered drugs: comparative activity of intracellular clodronate, propamidine, and ethylenediaminetetraacetic acid. Hepatology. 1996; 23:1239-1243.

30. VandenDriessche T, Vanslembrouck V, Goovaerts I, et al. Long-term expression of human coagulation factor VIII and correction of hemophilia A after in vivo retroviral gene transfer in factor VIII-deficient mice [see comments]. Proc Natl Acad Sci U S A. 1999;96:10379-10384.

31. Chuah MK, Brems H, Vanslembrouck V, Collen $\mathrm{D}$, Vandendriessche T. Bone marrow stromal cells as targets for gene therapy of hemophilia A. Hum Gene Ther. 1998;9:353-365.

32. Parks RJ, Graham FL. A helper-dependent system for adenovirus vector production helps define a lower limit for efficient DNA packaging. J Virol. 1997;71:3293-3298.
33. Morral N, O'Neal W, Rice K, et al. Administration of helper-dependent adenoviral vectors and sequential delivery of different vector serotype for long-term liver-directed gene transfer in baboons. Proc Natl Acad Sci U S A. 1999;96:12816-12821.

34. Schiedner G, Hertel S, Johnston M, Biermann V, Dries $\mathrm{V}$, Kochanek $\mathrm{S}$. Variables affecting in vivo performance of high-capacity adenovirus vectors. J Virol. 2002;76:1600-1609.

35. Pastore L, Morral N, Zhou H, et al. Use of a liver specific promoter reduces immune response to the transgene in adenoviral vectors. Hum Gene Ther. 1999;10:1773-1781.

36. Lozier JN, Metzger ME, Donahue RE, Morgan RA. Adenovirus-mediated expression of human coagulation factor IX in the rhesus macaque is associated with dose-limiting toxicity [see comments]. Blood. 1999;94:3968-3975.

37. Cichon G, Schmidt HH, Benhidjeb T, et al. Intravenous administration of recombinant adenoviruses causes thrombocytopenia, anemia and erythroblastosis in rabbits. J Gene Med. 1999;1: 360-371.

38. Lieber A, He CY, Meuse L, et al. The role of Kupffer cell activation and viral gene expression in early liver toxicity after infusion of recombinant adenovirus vectors. J Virol. 1997;71:8798-8807.

39. Balague C, Zhou J, Dai Y, et al. Sustained highlevel expression of full-length human factor VIII and restoration of clotting activity in hemophilic mice using a minimal adenovirus vector. Blood. 2000;95:820-828.

40. Chao H, Mao L, Bruce AT, Walsh CE. Sustained expression of human factor VIII in mice using a parvovirus-based vector. Blood. 2000;95:15941599.

41. Park F, Ohashi K, Kay MA. Therapeutic levels of human factor VIII and IX using HIV-1-based lentiviral vectors in mouse liver. Blood. 2000;96:11731176.

42. Evans GL, Morgan RA. Genetic induction of immune tolerance to human clotting factor VIII in a mouse model for hemophilia A. Proc Natl Acad Sci U S A. 1998;95:5734-5739.

43. Chuah MK, Van Damme A, Zwinnen $\mathrm{H}$, et al. Long-term persistence of human bone marrow stromal cells transduced with factor VIII-retrovira vectors and transient production of therapeutic levels of human factor VIII in nonmyeloablated immunodeficient mice. Hum Gene Ther. 2000;11: 729-738.

44. Pittman DD, Alderman EM, Tomkinson KN, Wang $\mathrm{JH}$, Giles AR, Kaufman RJ. Biochemical, immunological, and in vivo functional characterization of B-domain-deleted factor VIII. Blood. 1993;81: 2925-2935.

45. Connelly S, Andrews JL, Gallo-Penn AM, Tagliavacca $L$, Kaufman RJ, Kaleko M. Evaluation of an adenoviral vector encoding full-length human factor VIII in hemophiliac mice. Thromb Haemost. 1999;81:234-239.

46. Morsy MA, Gu M, Motzel S, et al. An adenoviral vector deleted for all viral coding sequences results in enhanced safety and extended expression of a leptin transgene. Proc Natl Acad Sci U S A. 1998;95:7866-7871.

47. Schnell MA, Zhang Y, Tazelaar J, et al. Activation of innate immunity in nonhuman primates following intraportal administration of adenoviral vectors. Mol Ther. 2001;3:708-722.

48. Zhang Y, Chirmule N, Gao GP, et al. Acute cytokine response to systemic adenoviral vectors in mice is mediated by dendritic cells and macrophages. Mol Ther. 2001;3:697-707.

49. Raper SE, Yudkoff M, Chirmule N, et al. A pilot study of in vivo liver-directed gene transfer with an adenoviral vector in partial ornithine transcarbamylase deficiency. Hum Gene Ther. 2002;13: 163-175.

50. Lozier JN, Csako G, Mondoro TH, et al. Toxicity of a first-generation adenoviral vector in rhesus macaques. Hum Gene Ther. 2002;13:113-124.

51. Gilles JG, Arnout J, Vermylen J, Saint-Remy JM. Anti-factor VIII antibodies of hemophiliac patients are frequently directed towards nonfunctional determinants and do not exhibit isotypic restriction. Blood. 1993;82:2452-2461.

52. Barrera P, Blom A, van Lent PL, et al. Synovial macrophage depletion with clodronate-containing liposomes in rheumatoid arthritis. Arthritis Rheum. 2000:43:1951-1959.

53. van Rooijen N, Bakker J, Sanders A. Transient suppression of macrophage functions by liposome-encapsulated drugs. Trends Biotechnol. 1997;15:178-185.

54. Ziegler RJ, Li C, Cherry M, et al. Correction of the nonlinear dose response improves the viability of adenoviral vectors for gene therapy of Fabry disease. Hum Gene Ther. 2002;13:935-945.

55. Kreppel F, Biermann V, Kochanek S, Schiedner G. A DNA-based method to assay total and infectious particle contents and helper virus contamination in high-capacity adenoviral vector preparations. Hum Gene Ther. 2002;13:1151-1156.

56. Ehrhardt A, Kay MA. A new adenoviral helperdependent vector results in long-term therapeutic levels of human coagulation factor IX at low doses in vivo. Blood. 2002;99:3923-3930. 